\title{
Hay Wells Syndrome: Report of an Extremely Rare Disorder
}

\author{
Pradyumna Pan ${ }^{1 *}$ and Ritika Pan ${ }^{2}$ \\ ${ }^{\prime}$ M.S (Surgery), M.Ch (Pediatric surgery), Ashish Hospital\& Research Centre, Jabalpur, Madhya Pradesh, 482001, India \\ ${ }_{2}^{2}$ Intern, Hitkarni Dental College \& Hospital, Jabalpur, Madhya Pradesh, 482001, India
}

\begin{abstract}
Hay-Wells syndrome also known as AEC syndrome (Ankyloblepharon-Ectodermal Dysplasia-clefting syndrome) is an uncommon form of ectodermal dysplasia initially described by Hay and Wells in 1976. AEC syndrome is an extremely rare disorder and fewer than 100 affected individuals have been described in the medical literature [1]. We report 22 days female with Hay wells syndrome.
\end{abstract}

Keywords: Ectodermal dysplasia syndrome, Hay Wells syndrome, Cleft palate, Cleft lip

\section{Introduction}

Ankyloblepharon-Ectodermal Defects-cleft lip/palate (AEC) syndrome is a form of ectodermal dysplasia, characterized by abnormal development of ectodermal tissues including the skin, hair, nails, teeth, and sweat glands. AEC syndrome is a rare condition with unknown prevalence. Ectodermal dysplasia group as a whole occur in about 1 in 100,000 new-borns. Two features that differentiate HWS from other ectodermal dysplasia are the presence of cleft palate and less often cleft lip. Secondly, the edges of the upper and lower eyelid are fused together by bands of fibrous tissue causing difficulty in opening the eyes. This condition is called ankyloblepharon filiforme adnatum.

\section{Case Report}

The present case report describes 22 days full term female child delivered vaginaly after an uneventful pregnancy. She is first born to nonconsanguineous parents and there were no similar cases in the family. She was brought with an inability to open both eyes and with deformity of lips and palate. Her weight was normal for her age. On examination, both eyes had thin bands of tissue attaching both eyelids (Figure 1). The bands are restricting the eyes from opening. There was no swelling over the lacrimal sac area. She had a bilateral cleft lip and total cleft palate (Figure 2). There were no structural limb abnormalities and no syndactyly. There were no noticeable skin and nail lesions. The child was feeding and thriving well. Laboratory tests were within normal limits. Chest radiography, ultrasound abdomen and echo heart revealed no abnormality. The bilateral bands of the eyes were divided under sedation on day 24 of life. The cleft lip was repaired at six months and cleft palate was done at 13 months of

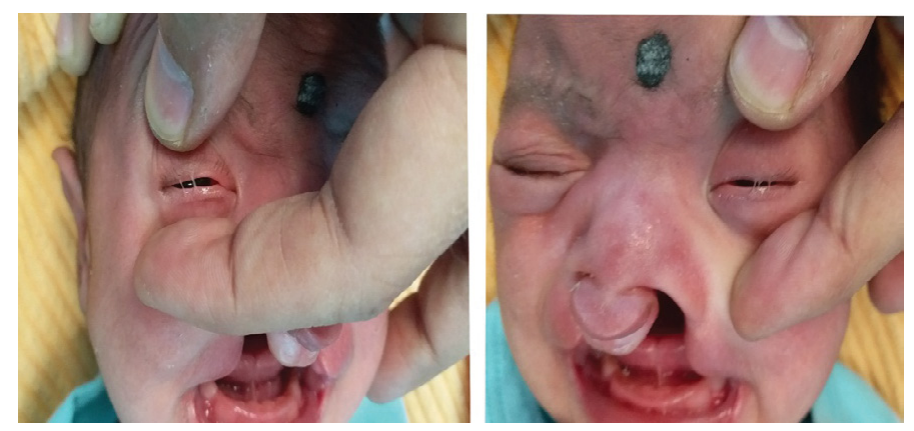

Figure 1: Clinical photo showing ankyloblepharon of both eyes.

*Correspondence to: Dr. Pradyumna Pan, M.S (Surgery), M.Ch (Pediatric surgery), Ashish Hospital \& Research Centre, Jabalpur, Madhya Pradesh, 482001, India, E-mail:dr_pan@rediffmail.com

Citation: Pan P, Pan R (2020) Hay Wells Syndrome: Report of an Extremely Rare Disorder. J Pediatr Congenit Dis 6(1): 101. DOI: https://doi.org/10.47275/23796707-101

Received: April 25, 2020; Accepted: May 12, 2020; Published: May 15, 2020

Copyright: (c) 2020 Pan P, et al. This is an Open Access article distributed under the terms of the Creative Commons Attribution 4.0 International License (CCBY) (http://creativecommons.org/licenses/by/4.0/) which permits commercial use, including reproduction, adaptation, and distribution of the article provided the original author and source are credited. 

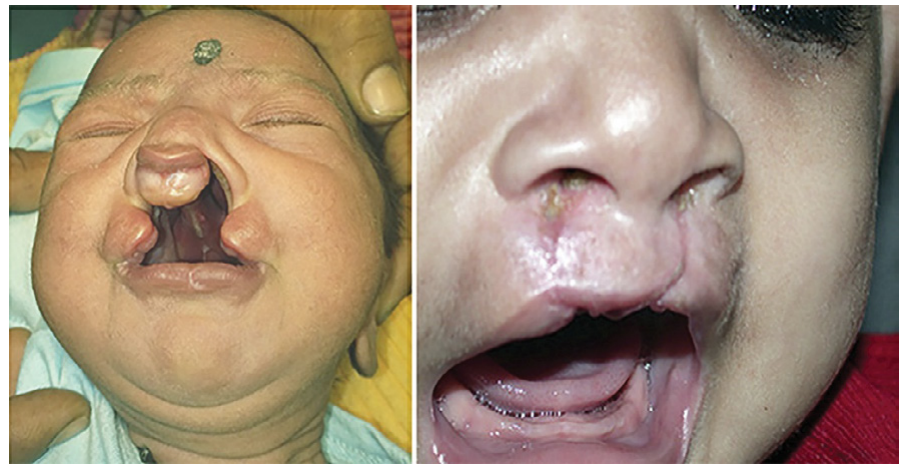

Figure 2: (A) Clinical photo showing the cleft lip and palate (B) showing the reconstructed cleft lip.
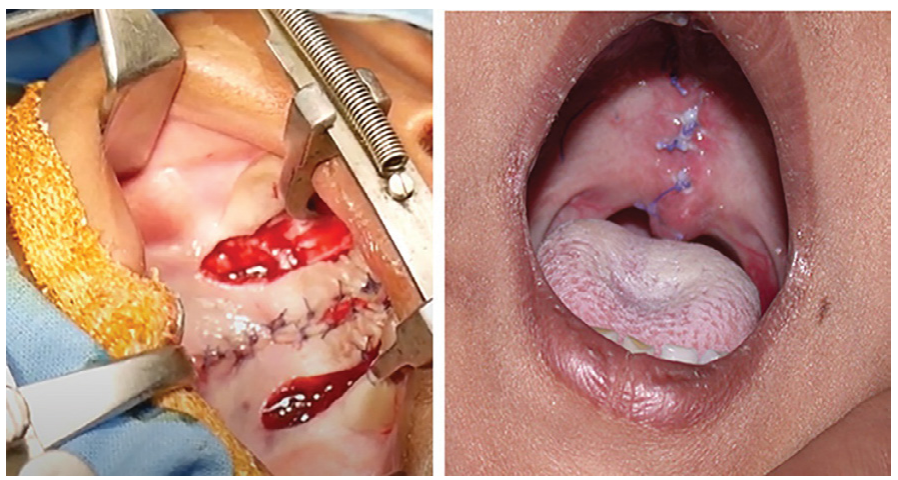

Figure 3: Operative photo showing the reconstructed cleft palate.

life. The speech therapy was started subsequently and the child was followed up, found to be developing according to her age. The child is regularly reviewed by the cleft team. Additional surgeries will be needed to improve the appearance of the teeth, mouth, lip and nose.

\section{Discussion}

AEC syndrome or HWS is one of the 150 known ED syndromes [2]. The EDs are a large group of clinically and genetically heterogeneous disorders characterized by the abnormal development of one or more appendages of epidermal (hair, nails, sweat glands) or oral ectodermal origin (teeth) [2]. Hay-Wells syndrome is a rare autosomal dominant, [3] caused by a missense mutation in the Sterile Alpha Motif (SAM) of the TP73L (p63) gene which encodes for a protein-protein interaction domain [3]. Located on the long arm of chromosome 3, the Tumor Protein 63 (TP63) gene is essential for proper development and homeostasis of stratified epithelia [3]. The p63 is thought to play a crucial role in the development and maintenance of the epidermis. Genetic testing recognizes changes in chromosomes, genes, or proteins. The outcome of a genetic test can confirm or rule out a suspected genetic condition or conclude a person's chance of developing or passing on a genetic disorder.

In HWS the hair is coarse and sparse, eyelashes are sparse or absent, nails may be missing or malformed, and teeth may be small and deformed [4]. There may be less number of sweat glands and they may produce little sweat, a condition known as hypohidrosis. Chronic inflammatory dermatitis of the scalp is a common symptom [4]. Management is usually difficult, often requiring aggressive wound care. Symptoms are noticeable at birth or become apparent when atypical development of teeth occurs [4]. Embryologically the eyelids remain fused until the fifth week of pregnancy after that they separate. The anomalies that occur between the $7^{\text {th }}$ and $15^{\text {th }}$ weeks of pregnancy may result in palpebral abnormalities [5]. Ankyloblepharon may also be present in trisomy 18 and CHAND (Curly Hair-Ankyloblepharon-Nail Dystrophy) syndrome and is associated with cardiac defects, hydrocephaly, imperforate anus and glaucoma [6].

The treatment concentrates on the symptoms present and suitable genetic counselling for parents. Surgery to be done to correct ankyloblepharon, cleft palate and cleft lip. Speech therapy may be required because of the cleft palate. Dental management is to be done for missing teeth. It is critical to know about reported associated anomalies so that patients can be monitored for these, and managed accordingly to improve the quality of life and prevent life-threatening complications. In general, the prognosis is excellent with the majority having normal life expectancy with negligible impact on the quality of life and psychosocial performance.

\section{Declaration of Patient Consent}

The authors certify that they have obtained all appropriate patient consent forms. In the form the patient's parent has given their consent for her images and other clinical information to be reported in the journal. The parents understand that their child name and initials will not be published and due efforts will be made to conceal her identity, but anonymity cannot be guaranteed.

\section{Financial Support and Sponsorship}




\section{Conflict of Interest}

There are no conflicts of interest.

\section{References}

1. 2017. AEC Syndrome. NORD.

2. 2011. Ankyloblepharon-ectodermal defects-cleft lip/palate syndrome. Genetics Home Reference.

3. McGrath JA, Duijf PH, Doetsch V, Irvine AD, de Waal R, et al. 2001. Hay-wells syndrome is caused by heterozygous missense mutations in the SAM domain of p63. Hum Mol Genet 10(3): 221-229.https://doi.org/10.1093/hmg/10.3.221

4. Kulkarni ML, Deshmukh S, Matani D, Gayatri K. 2006. Hay-wells syndrome of ectodermal dysplasia. Indian J Pediatr 73:101.https://doi.org/10.1007/bf02758272

5. Mohamed YH, Gong H, Amenyra T. 2003. Role of apoptosis in eyelid development. Exp Eye Res 76(1):115-123.https://doi.org/10.1016/s0014-4835(02)00269-5

6. Sharkey D, Marlow N, Stokes J. 2008. Ankyloblepharon filiforme adnatum. J Pediatr 152(4): 594.https://doi.org/10.1016/j.jpeds.2007.12.051 